\title{
Níveis de metáfora conceptual na Linguística Cognitiva
}

\author{
Levels of conceptual metaphor in Cognitive Linguistics
}

\section{Niveles de metáfora conceptual en la Lingüística Cognitiva}

\author{
Vitor Cordeiro Costa ${ }^{1}$ (D) https://orcid.org/0000-0003-0879-0951
}

\begin{abstract}
RESUMO: Este artigo sintetiza e discute propostas da Linguística Cognitiva que sugerem a existência de níveis de metáfora conceptual. O objetivo é mostrar como esse assunto específico se desenvolveu e destacar os avanços e as lacunas explicativas na teoria existente. Apresento um retrospecto conciso dos níveis de metáfora nas obras de Lakoff e Johnson, Grady, Clausner e Croft e Cameron e, então, a abordagem multinível de Kövecses. Expressões metafóricas com o domínio fonte CONSTRUÇÃO retiradas de um corpus de discursos de posse presidencial brasileiros são usadas para exemplificar e alimentar a discussão. Observa-se que os níveis de metáfora já estavam pressupostos nas obras de Lakoff e Johnson e Grady. Clausner e Croft explicitamente mostraram como a metáfora varia em níveis de esquematicidade e produtividade. Cameron fez uma interpretação metateórica de níveis de metáfora. Kövecses propôs que a metáfora envolve a relação entre estruturas em quatro níveis conceptuais e sugeriu níveis de análise ontológicos e contextuais. Argumento que a questão das unidades conceptuais envolvidas na metáfora e dos níveis de análise está presente na Linguística Cognitiva desde o início dessa área. Kövecses organizou os níveis de metáfora de maneira coerente, porém, persistem imprecisões na diferença entre frames e domínios.
\end{abstract}

PALAVRAS-CHAVE: Metáfora. Linguística Cognitiva. Esquematicidade.

ABSTRACT: This paper summarizes and discusses proposals in Cognitive Linguistics that suggest the existence of levels of conceptual metaphor. It aims to show the development of this particular topic and to highlight explanatory advances and gaps in the existing theory. I present a concise overview of levels of metaphor in the works of Lakoff and Johnson, Grady, Clausner and Croft, Cameron and then Kövecses's multilevel approach. Metaphorical expressions with BUILDING source domains extracted from a corpus of Brazilian inauguration speeches are used to exemplify and fuel discussion. I point out that Lakoff and Johnson's and Grady's theory already assumed the idea of levels of metaphor. Clausner and Croft explicitly showed how metaphors vary in their levels of

\footnotetext{
${ }^{1}$ Doutorando em Estudos Linguísticos pela Universidade Federal de Minas Gerais; Graduado em Letras e Mestre em Teoria Literária e Crítica da Cultura pela Universidade Federal de São João del-Rei. Professor no Instituto Federal do Sudeste de Minas Gerais. ORCID: https://orcid.org/0000-0003-0879-0951. Email: vitorccost@yahoo.com.br.
} 
schematicity and productivity. Cameron made a metatheoretical interpretation of levels of metaphor. Kövecses propounded that metaphor involves the relation between structures at four conceptual levels and suggested ontological and contextual levels of analysis. I argue that the issue of the conceptual units involved in metaphor and the levels of analysis has been present in Cognitive Linguistics from the outset. Kövecses organized the levels of metaphor coherently, but differences between domains and frames remain imprecise.

KEYWORDS: Metaphor. Cognitive Linguistics. Schematicity.

RESUMEN: Este artículo sintetiza y discute propuestas de la Lingüística Cognitiva que proponen la existencia de niveles de metáfora conceptual con el objetivo de mostrar cómo se desarrolla ese tema específico y destacar los avances y los huecos explicativos en la teoría existente. Presento una breve retrospectiva de los niveles de metáfora en las obras de Lakoff y Johnson, Grady, Clausner y Croft y Cameron y, finalmente, el abordaje multinivel de Kövecses. Expresiones metafóricas con el dominio fuente CONSTRUCCIÓN obtenidas de un corpus de discursos de toma de posesión de presidentes brasileños sirven para ejemplificar y fomentar la discusión. Se observa que los niveles de metáfora ya se presuponían en las obras de Lakoff y Jonhson y Grady. Clausner y Croft mostraron esa variación en niveles de esquematicidad y productividad. Cameron propuso una interpretación metateórica de niveles de metáfora. Kövecses planteó que la metáfora conlleva la relación entre estructuras en cuatro niveles conceptuales y sugirió niveles analíticos ontológicos y contextuales. Propongo que la cuestión de las unidades conceptuales y de los niveles analíticos forman parte de la Lingüística Cognitiva desde su principio. Kövecses organizó coherentemente los niveles de metáfora; pero todavía subsisten imprecisiones en la distinción entre frames y dominios.

PALABRAS CLAVE: Metáfora. Lingüística Cognitiva. Esquematicidad.

\section{Considerações iniciais e fundamentos prévios}

Na psicologia cognitiva, concepto é a unidade básica de conhecimento que nosso cérebro desenvolve (EVANS, 2007; EVANS; GREEN, 2006). Esse conhecimento surge quando nossa atenção se volta seletiva e repetidamente para algum componente da experiência e nós, então, integramos as memórias das várias experiências semelhantes ou relevantes que tivemos daquele componente (BARSALOU, 2012). Por isso, pode-se dizer que o sistema conceptual humano contém o conhecimento das pessoas sobre o mundo. De acordo com Barsalou (2012), esse conhecimento não é uma gravação da realidade espelhada na mente, mas, sim, um conjunto estruturado de elementos conceptuais interpretativos da percepção e da experiência humana. Na Linguística Cognitiva, acreditase que o sistema conceptual se organiza de várias formas, inclusive em "domínios", que englobam elementos coerentes de conhecimento e experiência em diversos graus de complexidade.

A teoria da metáfora conceptual se embasa na premissa de que o sistema conceptual é metafórico (LAKOFF; JOHNSON, 1980a). Nessa teoria, a metáfora deixou de ser uma 
propriedade linguística de enunciados com fins artísticos e estéticos e passou a ser definida como um fenômeno cognitivo em que um domínio conceptual mais abstrato (domínio alvo) é compreendido, isto é, cognitivamente interpretado, em termos de outro domínio experiencial mais básico (domínio fonte). Na definição clássica, a metáfora se estabelece pelo mapeamento entre aqueles dois domínios e não apenas entre conceptos isolados dos domínios. Sendo uma propriedade do pensamento, uma única metáfora conceptual pode se realizar, se instanciar, linguisticamente na forma de várias expressões metafóricas. Por exemplo, a metáfora SISTEMA COMPLEXO É CONSTRUÇÃO² dá origem às expressões metafóricas (1) a (4), a seguir, com grifos meus, retiradas de um corpus de discursos de posse presidencial brasileiros (COSTA, 2015, 2017):

1. "Sob essa crença, destaco os alicerces de nosso governo: eficiência administrativa, retomada do crescimento econômico..."

2. "Com a paciência dos justos, recuperaram os postulados éticos que cimentam e suportam a estrutura dos Estados."

3. "O Brasil precisa fazer, em todos os domínios, um mergulho para dentro de si mesmo [...]. Fazer esse mergulho não significa fechar as portas $e$ janelas ao mundo."

4. "Quando muitos duvidavam se seríamos capazes de colocar nossa própria casa em ordem, nós começamos a arrumá-la nestes dois anos."

Observamos nesses exemplos que entidades categorizadas como complexas e abstratas (respectivamente governo, Estado, Brasile, por inferência, administração pública) são compreendidas em termos do domínio mais concreto de CONSTRUÇÃO. Desse modo, conceptualizamos o governo como possuindo alicerces, Estados como tendo estrutura e postulados éticos que o cimentam; Brasil como tendo portas e janelas; e organizar a administração pública como colocar nossa própria casa em ordem. Dentre várias razões, boa parte do sucesso da teoria da metáfora conceptual se deve à sua capacidade de apresentar evidências linguísticas e empíricas para suas afirmações sobre o sistema conceptual (GIBBS JUNIOR, 2017) e de dar uma resposta para a questão cognitivista de como se constrói a significação das abstrações na mente (KÖVECSES, 2017).

Os mesmos excertos (1) a (4) servem para exemplificar uma aparente antinomia na base da descrição do sistema conceptual. Em (1), alicerce evoca esquemas imagéticos de

\footnotetext{
2 Na Linguística Cognitiva, é convenção metalinguística representar conceptos, estruturas conceptuais, etc., usando os recursos tipográficos de versalete ou caixa alta, que funcionam como etiquetas de uma entidade mental. Por não serem termos linguísticos, eles não são flexionados como palavras da língua. "É" não é interpretado como o verbo ser, mas como operador semântico-cognitivo metalinguístico que representa o mapeamento entre dois domínios conceptuais. Nesse mesmo sentido, os termos técnicos "concepto" e seus derivados não devem ser confundidos com outras palavras como conceito, conceituale conceitualizar.
} 
OBJETO ESTRUTURADO, APOIO e VERTICALIDADE, que parecem ser mais abstratos do que as portas e janelas evocadas em (3). Embora se diga que a metáfora envolve a projeção entre dois domínios, nem toda informação disponível no domínio fonte é mapeada no alvo. A metáfora conceptualiza apenas alguns aspectos do concepto, oferecendo uma definição parcial (LAKOFF; JOHNSON, 1980b). Segundo Kövecses (2017), para explicar isso, as propostas envolvem (a) restringir o que pode ser mapeado entre os domínios ou (b) estreitar o domínio fonte participante da metáfora.

Ainda assim, o domínio parece ser uma estrutura conceptual muito ampla, por ser altamente inclusiva e insuficiente para explicar variações na esquematicidade das metáforas, como as apresentadas acima. A imprecisão explicativa tem se destacado pelo uso de termos distintos feito por pesquisadores da área para se referir às estruturas conceptuais na metáfora (CIENKI, 2007). Domínio é o mais comum, mas tem sido substituído por (ou diretamente relacionado a) esquemas, scripts, cenas, frames, espaços mentais, cenários, modelos cognitivos idealizados. Cada um desses conceitos traz consigo uma teorização distinta, dependendo do autor. Isso gera uma proliferação que, para Kövecses (2017), esconde a dificuldade real de identificar as unidades apropriadas que participam das metáforas, haja vista que o sistema conceptual é estruturado em níveis hierárquicos.

Neste artigo, sintetizo e discuto propostas que sugerem a existência de níveis de metáfora conceptual. Na seção a seguir, faço um breve retrospecto de teorizações sobre níveis de metáfora, ainda que não se apresentassem explicitamente como tal, nas obras de Lakoff e Johnson (1980a, 1980b), Grady (1997a, 1997b), Clausner e Croft (1997) e Cameron (1999). Na terceira seção, discuto a proposta mais recente de Kövecses (2017), chamada "abordagem multinível da metáfora conceptual", segundo a qual as metáforas envolvem estruturas ou unidades conceptuais em diferentes níveis de esquematicidade. Para alimentar essa discussão, uso exemplos de expressões metafóricas com o domínio fonte CONSTRUÇÃO encontradas em um corpus de discursos de posse presidencial compilado anteriormente (COSTA, 2015, 2017). A quarta e última seção traz uma avaliação panorâmica do desenvolvimento da ideia de níveis de metáfora e as perspectivas de estudos futuros.

Com isso, pretendo fazer uma contribuição de caráter eminentemente didático e bibliográfico. Do lado didático, por tratar exclusivamente do tema dos níveis de metáfora, 
dando-lhe uma certa ordem em meio à profusão de estudos sobre metáfora conceptual e mostrando seu desenvolvimento. Portanto, este artigo não tem a ambição de ser uma revisão sistemática e exaustiva da literatura, mas de destacar as teorias mais relevantes para avaliar os avanços e as lacunas recentes. Do lado da literatura científica, por ajudar a preencher uma omissão bibliográfica sobre o assunto em português brasileiro e a fomentar a sua abordagem, ainda insuficiente na Linguística Cognitiva ${ }^{3}$, salientando alguns pontos que precisam ser mais bem explicados e investigados futuramente.

\section{Propostas anteriores de níveis de metáfora}

Na obra seminal de Lakoff e Johnson (1980a, 1980b), que completa quarenta anos, já estava implícita uma diferenciação das metáforas por esquematicidade, embora esse não fosse o foco dos autores. As metáforas denominadas "orientacionais" conceptualizam um domínio alvo em termos de todo um domínio fonte da orientação espacial, como na frase Eles estão meio para baixo hoje. As "metáforas ontológicas" se valem de um domínio fonte concreto para dar status de ENTIDADE ou SUBSTÂNCIA a um domínio fonte abstrato ( $E$ preciso combater a inflação). Elas se diferenciam das "metáforas estruturais", que projetam uma ATIVIDADE em termos de outra ATIVIDADE. A gradação em níveis metafóricos está no fato de que uma ORIENTAÇÃO é muito mais esquemática do que uma ENTIDADE; e uma ATIVIDADE é necessariamente maior do que uma ENTIDADE, porque a ATIVIDADE envolve diversos participantes, relações entre estes, etc. Assim, Lakoff e Johnson (1980a) apresentaram exemplos que ilustram a diferença para a qual chamo atenção: VIDA É CONTÊINER (Ele leva uma vida muito vazia) depende de estruturas mentais mais esquemáticas ou abstratas do que IDEIA É PESSOA (Freud é o pai da psicanálise), que são diferentes daquelas presentes em VER É ENTENDER (Eu vejo a coisa de outro jeito!).

Grady (1997a, 1997b) avançou substancialmente na questão ao distinguir "metáforas primárias" de "metáforas complexas". As metáforas primárias se formam pela associação inconsciente de conceptos igualmente básicos, de domínios diferentes, que se correlacionam de maneira recorrente pela experiência. Desse modo, Grady, de um lado, afirmou que as metáforas primárias são associações de conceptos de domínios diferentes

\footnotetext{
${ }^{3}$ Esses argumentos podem ser atestados, a título de amostra, pela leitura de um recente apanhado sobre estudos da metáfora no Brasil, feito por Avelar e Cienki (2020). O próprio artigo-editorial está publicado em língua inglesa e nele não há menção a níveis de metáfora.
} 
(e não de domínios inteiros); de outro, se afastou da teoria inicial ao prever que a metáfora primária não associa apenas um domínio concreto a um abstrato, mas conceptos igualmente básicos. Sendo igualmente básicos, a diferença entre domínio fonte e domínio alvo está em seus "graus de subjetividade", ou seja, dependendo do quão diretamente perceptual a fonte está em relação ao alvo (LIMA, 2006; GRADY, 2007). A unificação de várias metáforas primárias origina as metáforas complexas. Por exemplo, as metáforas complexas expressas pelos enunciados (5) a (7) abaixo, retirados dos discursos de posse presidencial, dependem da metáfora primária QUANTIDADE É POSIÇÃO ou QUANTIDADE É ELEVAÇÃO VERTICAL:

5. "As reservas internacionais estão em patamar histórico, na casa dos 370 bilhões de dólares."

6. "Em todos os anos do meu primeiro mandato, a inflação permaneceu abaixo do teto da meta e assim vai continuar."

7. "Encaminhamos ao Congresso Nacional uma proposta de emenda constitucional com teto para as despesas públicas."

Enquanto a teoria de Grady (1997a, 1997b) enfocou níveis gerados pelos graus de subjetividade da experiência perceptual, Clausner e Croft (1997) publicaram, no mesmo ano, uma teorização robusta - e depois praticamente esquecida pelos estudos da metáfora - sobre como os princípios de esquematicidade e produtividade, observados nas estruturas morfológicas, também valem para as metáforas. Os autores defendem a tese de que as metáforas conceptuais variam em esquematicidade, de maneira que as relações entre os domínios fonte e alvo podem ser vistas como generalizações de mapeamentos específicos. A esquematicidade é interpretada como "a abrangência de conceptos do domínio fonte (ou alvo) consistentes com o esquema", e a produtividade como "a proporção da abrangência de um esquema que pode ser instanciado em expressões [metafóricas]" (CLAUSNER; CROFT, 1997, p. 257, tradução minha). Se variam em esquematicidade, as metáforas podem ser agrupadas e organizadas em uma hierarquia taxonômica, exemplificada assim: a metáfora de nível genérico EVENTO É AÇÃO pode se instanciar na metáfora de nível específico MORTE É PARTIDA e ser expressa com os enunciados Ela nos deixou ou Ela se foi. O trabalho de Clauser e Croft (1997) se diferencia das demais obras sobre a estrutura do sistema conceptual ao demonstrar como formas e significados se organizam cognitivamente com base nos mesmos princípios. 
Em outra direção, ao buscar um modo de operacionalizar ${ }^{4}$ o conceito de metáfora para pesquisas aplicadas focadas no uso, Cameron (1999) apresentou uma distinção de níveis de metáfora que, apesar das fragilidades que a própria autora reconhece, é útil para esclarecimento sobre as propostas anteriores e sobre a de Kövecses (2017), mais adiante. Cameron (1999) separou três níveis de investigação em relação a fenômenos mentais. 0 primeiro é o nível teórico da análise, de formular teorias elegantes e coerentes com uma lógica particular, no qual uma preocupação central é o processo de identificar e categorizar as metáforas. O segundo é o nível processual da análise, de investigar a estruturação e ativação de domínios conceptuais através da metáfora e a interpretação desta, no qual o foco é estudar a metáfora em seu contexto discursivo. O terceiro é o nível neural - que na época da publicação estava em estágio inicial e Cameron aborda brevemente -, no qual se investiga como a atividade neural promove o processamento metafórico no primeiro e no segundo nível indicados. A proposta de Cameron (1999), portanto, era de natureza metateórica e não postulou níveis cognitivos, apesar de estabelecer níveis empíricos de pesquisa em metáfora.

\section{Proposta multinível de metáfora de Kövecses}

No desenvolvimento da teoria da metáfora ao longo das décadas de 1990, 2000 e 2010, as propostas abordadas na seção anterior ganharam repercussão em outros trabalhos, apesar de o termo "níveis de metáfora" ter tido uso restrito e genérico, como se exemplifica pela leitura de MacArthur et al. (2012), Steen (2007) e Yu (2008). A formulação recente que teoriza a metáfora especificamente como fenômeno que ocorre em níveis se encontra nas obras de Kövecses (2010, 2015, 2017, 2020), cujas propostas abarcam tanto a organização metodológica de como analisar as metáforas $(2010,2015)$ quanto a explicação do processo cognitivo propriamente dito (2017 e 2020)5. A abordagem multinível da metáfora conceptual surge como uma resposta de Kövecses aos questionamentos sobre a natureza da estrutura conceptual envolvida no mapeamento metafórico e como tentativa de esclarecer certa confusão teórica e terminológica, os quais indiquei na introdução deste

\footnotetext{
${ }^{4}$ Em metodologia científica, entende-se por operacionalização a tentativa de formular um conceito teórico de tal maneira que seja possível submetê-lo a testes empíricos ou à falsificação. Para Cameron (1999), isso demanda definir e categorizar os fenômenos relevantes e, separado o que conta do que não conta como evidência, restringir o que vai ser analisado.

5 Considerando que o livro de 2020 é recém-lançado, faço apenas uma menção panorâmica a ele, pois sua avaliação ainda depende de uma análise mais cuidadosa das propostas do autor.
} 
artigo.

Kövecses (2017) parte da premissa da psicologia cognitiva de que o sistema conceptual se organiza em níveis (superordenado, nível básico, subordinado) num continuum de esquematicidade. A tese é de que a metáfora envolve simultaneamente a relação entre estruturas em diferentes níveis ou camadas de especificação, numa hierarquia mental contínua, gradativa e sem bordas rígidas. $\mathrm{O}$ autor afirma que se podem distinguir quatro níveis conceptuais participantes da metáfora: esquema imagético; domínio; frame; espaço mental. Essa sequência indica os níveis do mais esquemático (esquema imagético) ao menos esquemático (espaço mental) e, inversamente, do menos específico (esquema imagético) ao mais específico (espaço mental). Os esquemas imagéticos, os domínios e os frames são do plano da memória de longo prazo, e os espaços mentais, da memória de trabalho. A Figura 1, abaixo, é uma compilação e adaptação dos diagramas de Kövecses (2017) para ilustrar como esses níveis se organizam. Observe que os níveis são taxonômicos (um está incluso no outro) e que, nos mapeamentos fonte-alvo, a espessura da linhas indica o nível de esquematicidade proeminente na metáfora.

Figura 1- Mapeamento metafórico, ativação e estruturação entre níveis

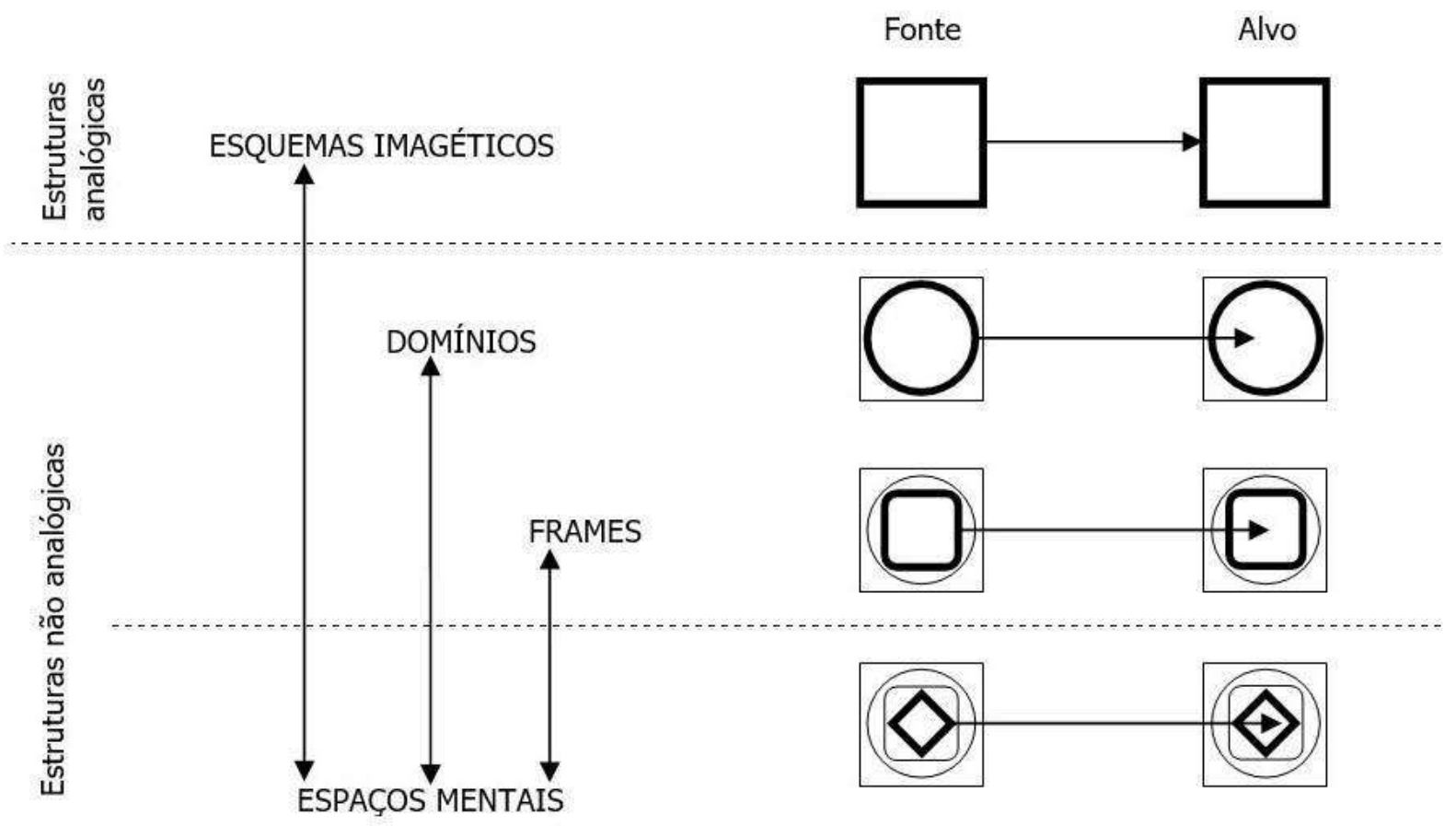

Fonte: Compilado, traduzido e adaptado pelo autor, a partir de Kövecses (2017, p. 330; 343).

Os esquemas imagéticos são estruturas pré-conceptuais imagísticas que dão sentido à experiência sensorial na forma de gestalten analógicas com poucas partes. Exemplos de 
esquemas imagéticos são as relações PARTE-TODO, DENTRO-FORA e VERTICALIDADE. Já os domínios são reinterpretados por Kövecses (2017) como uma área coerente da conceptualização em relação à qual unidades semânticas são compreendidas. Os domínios têm natureza proposicional e são mais ricos em informação, sendo compostos de vários esquemas imagéticos e frames que caracterizam seus diferentes aspectos. Nesse sentido, os frames são menos esquemáticos e especificam aspectos dos domínios na forma de sistemas de conceptos compostos de papéis e de relações entre esses papéis. A título de ilustração, o frame COMPRAR está num nível menos esquemático em relação ao domínio RELAÇÃO COMERCIAL. Por fim, os espaços mentais são montagens parciais na memória de trabalho, construídos online na situação comunicativa, para fins locais, e contêm instanciações específicas dos papéis e das relações dos frames.

Então, como ocorre o mapeamento metafórico na abordagem multinível? O mapeamento se dá entre fontes e alvos no mesmo nível de esquematicidade: esquemas imagéticos fonte são projetados em esquemas imagéticos alvo; frames fonte em frames alvo e assim por diante. O mapeamento num nível licencia os mapeamentos nos demais níveis, licenciando também os mapeamentos nos outros níveis evocados por palavras usadas metaforicamente no texto. Portanto, as metáforas não estão ligadas a uma única estrutura conceptual, mas são "complexos de todos esses quatro [níveis] ao mesmo tempo" (KÖVECSES, 2017, p. 344, tradução minha). Cada nível traz um grau diferente de especificação para o fenômeno da construção de sentido. Abaixo, reapresento o trecho (3) e introduzo os excertos de (8) a (10), extraídos do corpus de discursos de posse presidencial brasileiros, para ilustrar algumas dessas afirmações:

3. "O Brasil precisa fazer, em todos os domínios, um mergulho para dentro de si mesmo [...]. Fazer esse mergulho não significa fechar as portas $e$ janelas ao mundo."

8. "... esse projeto [político de América do Sul] repousa em alicerces econômico-comerciais que precisam ser urgentemente reparados e reforçados."

9. "... iniciamos a reforma da economia. Por isso mesmo, construímos base mais sólida para seguir adiante."

10. "Um país [...] que está construindo a estabilidade e tem agora pela frente o desafio de edificar uma sociedade mais igualitária."

Seguindo as análises de Kövecses (2017) da maneira mais próxima possível, essas expressões evocam cognitivamente mapeamentos metafóricos em diferentes níveis. No nível dos esquemas imagéticos, temos as projeções SISTEMA ABSTRATO COMPLEXO É 
OBJETO VERTICAL E SISTEMA ABSTRATO COMPLEXO É OBJETO-TODO COM PARTES, as quais licenciam e integram os níveis seguintes. Na escala dos domínios, essas projeções são especificadas por meio dos mapeamentos SISTEMA ABSTRATO COMPLEXO É OBJETO FÍSICO; ESTRUTURA DE SISTEMA É ESTRUTURA FÍSICA DE CONSTRUÇÃO; PARTE DE SISTEMA É PARTE DE CONSTRUÇÃO (especialmente nos trechos 3, 8 e 9); CRIAR É CONSTRUIR e MODIFICAR ENTIDADE É CONSTRUIR (especialmente nos trechos 9 e 10).

No próximo nível, os elementos e relações dos frames CONSTRUÇÃO e CONSTRUIR servem para conceptualizar o domínio alvo, oferecendo especificações. Os substantivos portas, janelas e alicerces evocam o frame CONSTRUÇÃO e os verbos construir e edificar evocam o frame CONSTRUIR, que têm os elementos: CONSTRUTOR que reúne MATERIAL para dar origem a um CONSTRUTO. O frame evocado também tem, em plano de fundo, DESCRIÇÃO (características do CONSTRUTO), LUGAR, TEMPO e seus eventuais BENEFICIÁRIO e CONSEQUÊNCIA (entidade para a qual se faz CONSTRUTO e as consequências da ação, respectivamente). Os mapeamentos entre elementos do frame fonte e do frame alvo nas expressões metafóricas analisadas estão dispostos na Figura 2 para melhor visualização.

Figura 2 - Problema na codificação de símbolos dentro da tabela. Os quadrados com interrogação devem ser substituídos por setas

\begin{tabular}{|c|c|c|c|}
\hline Elementos de frame fonte & & Elementos de frame alvo & Excerto \\
\hline CONSTRUÇÃO & 目 & $\begin{array}{c}\text { PAÍS } \\
\text { POLÍTICA EXTERNA } \\
\text { ESTABILIDADE ECONÔMICA } \\
\text { SOCIEDADE }\end{array}$ & $\begin{array}{l}(3) \\
(8) \\
(9,10) \\
(10)\end{array}$ \\
\hline $\begin{array}{l}\text { PARTE/ABERTURA DA CONSTRUÇÃO } \\
\text { PASSAGEM INTERNO-EXTERNO }\end{array}$ & 回 & RELAÇÕES INTERNACIONAIS & (3) \\
\hline $\begin{array}{c}\text { SUSTENTAÇÃO DA CONSTRUÇÃO } \\
\text { CONSTRUIR }\end{array}$ & 回 & $\begin{array}{c}\text { PREMISSA } \\
\text { SITUAÇÃO ECONÔMICA } \\
\text { CRIAR SITUAÇÃO } \\
\text { MODIFICAR ENTIDADE }\end{array}$ & $\begin{array}{l}(8) \\
(9) \\
(9) \\
(10)\end{array}$ \\
\hline
\end{tabular}

Fonte: Elaborado pelo autor.

A metáfora alcança seu nível máximo de especificação no âmbito dos espaços mentais particulares da enunciação de cada trecho. Conforme sugere Kövecses (2017), os espaços mentais se caracterizam, em (3), por BRASIL SE RELACIONANDO COM OUTROS PAÍSES É BRASIL DE PORTAS E JANELAS ABERTAS; em (8), por PREMISSA ECONÔMICA DANIFICADA É ALICERCE DANIFICADO; em (9), por CONDIÇÃO ECONÔMICA MAIS SÓLIDA 
É BASE MAIS SÓLIDA; em (10), por PAÍS EDIFICANDO SOCIEDADE IGUALITÁRIA É PAÍS EDIFICANDO CONSTRUÇÃO. No nível dos espaços mentais, estão os fatores contextuais responsáveis pelas inferências e consequências desses enunciados, por exemplo, terem sido proferidos por enunciadores específicos. Neste texto, acompanhando os objetivos de Kövecses (2017), restringi-me a analisar as dimensões convencionais das metáforas, por esse motivo, abordei aspectos menos contextuais dos espaços mentais envolvidos.

Assim como Cameron (1999), Kövecses $(2010,2015,2017,2020)$ se preocupou em teorizar a metáfora para além do processamento cognitivo stricto sensu, abordando-a em níveis de contexto e em níveis ontológicos correlacionados aos tipos de estrutura conceptual, de significado e de memória. Segundo o autor, a metáfora é influenciada por e/ou usada em quatro tipos de contexto: situacional, discursivo, corporal e conceptualcognitivo (KÖVECSES, 2015, 2020). No que tange aos níveis ontológicos esboçados em obras anteriores (KÖVECSES, 2010, 2015), eles foram correlacionados aos níveis de metáfora na expansão da teoria e são de três ordens. O nível subindividual corresponde a aspectos universais da corporalidade humana e está ligado aos esquemas imagéticos. 0 nível supraindividual corresponde a como padrões metafóricos descontextualizados se refletem numa língua e numa cultura e está ligado aos domínios e aos frames. Por sua vez, o nível individual corresponde a como falantes individuais de uma língua usam o sistema cognitivo metafórico e está ligado aos espaços mentais (KÖVECSES, 2010, 2017). Kövecses afirma que essa formulação seria capaz de resolver críticas cruciais feitas à versão clássica da teoria, como a dúvida sobre a estrutura conceptual envolvida na metáfora, a estaticidade do modelo e o papel do contexto e da criatividade dos falantes.

\section{Considerações finais e persepctivas futuras}

O retrospecto das propostas de níveis de metáfora evidencia que, desde as obras fundadoras, pesquisadores no campo da Linguística Cognitiva têm buscado solucionar o problema conceitual dos domínios experienciais e oferecer respostas para a questão teórica das unidades ou estruturas conceptuais envolvidas nas metáforas. As respostas têm caminhado progressivamente no sentido de esclarecer as conexões entre os mapeamentos metafóricos. $O$ fato de que algumas expressões metafóricas permitem depreender mapeamentos mais ou menos esquemáticos não tem passado despercebido, fazendo com que o postulado de o sistema conceptual ter níveis de esquematicidade se reflita na teoria 
da metáfora. Além disso, como as relações da teoria da metáfora com estudos culturais, sociodiscursivos e textuais têm sido bastante fortes desde o início, os pesquisadores também têm feito propostas de níveis de contexto e de níveis metodológicos de análise discursivo-textual.

Em particular, a proposta de Clausner e Croft (2017) tem a vantagem de permitir interfaces mais diretas dos estudos da metáfora conceptual com a teoria baseada no uso (BYBEE, 2013) e com estudos em gramática de construções (CROFT, 2007; GOLDBERG, 1995, 2006) na medida em que postula premissas comuns para esses fenômenos. Já a proposta de Kövecses (2017) para uma abordagem multinível da metáfora conceptual tem a conveniência de se valer de teorias já existentes e consolidadas da Linguística Cognitiva, reinterpretando-as, dando-Ihes maior refinamento e, de maneira parcimoniosa, evitando postular novos conceitos. Apesar de Kövecses não afirmar isto, a tese de que as metáforas variam em esquematicidade já estava presente no trabalho de Grady (1997a, 1997b) e explicitada por Clausner e Croft (1997).

Kövecses (2017) é parcialmente bem sucedido em clarificar certas confusões terminológicas apontadas na literatura da Linguística Cognitiva. Se antes Kövecses (2010) definia a metáfora como projeção entre modelos cognitivos idealizados e/ou entre domínios, agora (KÖVECSES, 2017) os modelos cognitivos não estão mais presentes e a metáfora ocorre entre quatro níveis. Embora tente resolver a conceituação dos domínios, o autor mantém o problema em alguma medida ao afirmar que a "definição dos domínios não faz distinção entre domínios e frames ou modelos cognitivos idealizados [...]. A única maneira de distinguir os dois é em termos de esquematicidade" (KÖVECSES, 2017, p. 325, tradução minha). Ainda assim, Kövecses avançou ao ordenar várias propostas de níveis cognitivos em um modelo aparentemente mais coerente e metodologicamente mais organizado, que ainda precisa ser submetido a avaliações baseadas em um número maior de metáforas.

Nesse sentido, deve-se lembrar que a Linguística Cognitiva tem sido incisivamente questionada e criticada (DĄBROWSKA, 2016) por confiança excessiva na introspecção do pesquisador, desacompanhada de dados obtidos com outros métodos; por falta de testagem de hipóteses em privilégio de sua formulação ${ }^{6}$; por falta de consideração concreta

\footnotetext{
${ }^{6}$ Dąbrowska (2016, p. 484, tradução minha) jocosamente alerta: "Precisamos derivar predições testáveis das nossas hipóteses, realizar os testes e refinar as hipóteses quando necessário. Se não fizermos isso, as discussões sobre explicações alternativas vão se degenerar em bate-boca de parquinho do tipo 'a minha teoria é mais bonita que a sua' ou 'as minhas intuições são mais fortes que as suas'"'.
} 
pelo "compromisso cognitivo" ao não se atentar para o que outros campos do saber têm a dizer sobre a cognição humana e não mostrar os vínculos das análises com informações sobre o processamento mental da linguagem e do conhecimento para validar a realidade cognitiva dos conceitos. Em maior ou menor medida, as teorias que abordei neste texto também têm essas lacunas, as quais, longe de invalidarem a ideia de níveis de metáfora, servem para mostrar o quão amplas e variadas são as possibilidades e necessidades de estudos a serem feitos para oferecer explicações mais refinadas sobre a metáfora conceptual.

\section{Referências}

AVELAR, M.; CIENKI, A. Metaphors we live by in Brazil: anthropophagic notes on classic and contemporary approaches to metaphor in the Brazilian scientific-academic context. Revista de Estudos da Linguagem, Belo Horizonte, v. 28, n. 2, p. 667-688, 2020. DOI: http://dx.doi.org/10.17851/2237-2083.28.2.667-688.

BARSALOU, L. W. The human conceptual system. In: SPIVEY, M. J.; MCRAE, K.; JOANISSE, M. F. (ed.). The Cambridge Handbook of Psycholinguistics. New York: Cambridge University Press, 2012. p. 239-258.

BYBEE, J. L. Usage-based theory and exemplar representations of constructions. In: HOFFMANN, T.; TROUSDALE, G. (ed.). The Oxford Handbook of Construction Grammar. Oxford: Oxford University Press, 2013. p. 52-66.

CAMERON, L. Operationalising 'metaphor' for applied linguistic research. In: LOW, G. et alii (ed.). Researching and applying metaphor. Cambridge: Cambridge University Press, 1999. p. 3-28.

CIENKI, A. Frames, idealized cognitive models, and domains. In: GEERAERTS, D.; CUYCKENS, H. (ed.). The Oxford Handbook of Cognitive Linguistics. Oxford: Oxford University Press, 2007. p. 170-187.

CLAUSNER, T. C.; CROFT, W. Productivity and schematicity in metaphors. Cognitive Science, Norwood, v. 21, n. 3, p. 247-282, July/Aug. 1997. DOI: https://doi.org/10.1207/s15516709cog2103_1.

COSTA, V. C. A palavra Brasil em discursos de posse presidencial da Nova República: panorama sociocognitivo (1990-2011). 2015. Dissertação (Mestrado em Teoria Literária e Crítica da Cultura) - Universidade Federal de São João del-Rei, São João del-Rei, 2015. DOIhttps://dx.doi.org/10.13140/RG.2.2.27541.78561 .

COSTA, V. C. A cultura das metáforas e frames de construção em discursos de posse presidencial brasileiros. In: CONGRESSO INTERNACIONAL SOBRE METÁFORA NA LINGUAGEM E NO PENSAMENTO, 6., 2017, Salvador. Anais [...]. Salvador: UFBA, 2017. p. 35. 
CROFT, W. Construction grammar. In: GEERAERTS, D.; CUYCKENS, H. (ed.). The Oxford handbook of cognitive linguistics. Oxford: Oxford University Press, 2007. p. 463-508.

DABRROWSKA, E. Cognitive linguistics' seven deadly sins. Cognitive Linguistics, [s. I.], v. 27, n. 4, p. 479-491, 2016. DOI: https://doi.org/10.1515/cog-2016-0059.

EVANS, V. A Glossary of cognitive linguistics. Edinburgh: Edinburgh University Press, 2007.

EVANS, V.; GREEN, M. Cognitive linguistics. an introduction. Edinburgh: Edinburgh University Press, 2006.

GIBBS JUNIOR, R. W. Metaphor wars: conceptual metaphors in human life. Cambridge: Cambridge University Press, 2017.

GOLDBERG, A. E. Constructions: a construction grammar approach to argument structure. Chicago: The University of Chicago Press, 1995.

GOLDBERG, A. E. Constructions at work: the nature of generalization in language. New York: Oxford University Press, 2006.

GRADY, J. E. Foundations of meaning: primary metaphors and primary scenes. 1997. 299 f. Tese (Doctor of Philosophy in Linguistics) - Graduate Division of the University of California, Berkeley, 1997a. Disponível em: https://escholarship.org/uc/item/3g9427m2. Acesso em: 12 nov. 2020.

GRADY, J. E. Theories are buildings revisited. Cognitive Linguistics, [s. I.], v. 8, n. 4, p. 267-290, 1997b. DOI: https://doi.org/10.1515/cogl.1997.8.4.267.

GRADY, J. E. Metaphor. In: GEERAERTS, D.; CUYCKENS, H. (ed.). The Oxford handbook of cognitive linguistics. Oxford: Oxford University Press, 2007. p. 188-213.

KÖVECSES, Z. Metaphor: a practical introduction. $2^{\text {nd }}$ ed. Oxford: Oxford University Press, 2010.

KÖVECSES, Z. Where metaphors come from: reconsidering context in metaphor. Oxford: Oxford University Press, 2015.

KÖVECSES, Z. Levels of metaphor. Cognitive Linguistics, [s. I.], v. 28, n. 2, p. 321-347, 2017. DOI: https://doi.org/10.1515/cog-2016-0052.

KÖVECSES, Z. Extended conceptual metaphor theory. Cambridge: Cambridge University Press, 2020.

LAKOFF, G.; JOHNSON, M. Metaphors we live by. Chicago: The University of Chicago Press, 1980a.

LAKOFF, G.; JOHNSON, M. The metaphorical structure of the human conceptual system. Cognitive Science, [s. l.], v. 4, n. 2, p. 195-208, 1980b. DOI:

https://doi.org/10.1016/S0364-0213(80)80017-6. 
LIMA, P. L. C. About primary metaphors. DELTA, São Paulo, v. 2, n. esp., p. 109-122, 2006. DOI http://dx.doi.org/10.1590/S0102-44502006000300009 .

MACARTHUR, F. et alii (ed.). Metaphor in use: context, culture and communication. Amsterdam: John Benjamins, 2012.

STEEN, G. J. Finding metaphor in grammar and usage: a methodological analysis of theory and research. Amsterdam: John Benjamins, 2007.

YU, N. Metaphor from body and culture. In: GIBBS JR, R. (ed.). The Cambridge handbook of metaphor and thought. Cambridge: Cambridge University Press, 2008. p. 247-261.

Submetido em: 28 nov. 2020. Aceito em: 15 mar. 2021. 